\title{
Transcatheter radiofrequency pulmonary artery denervation in swine: the evaluation of lesion degree, hemodynamics and pulmonary hypertension inducibility
}

Natalia S. Goncharova*, Heber Ivan Condori Leandro, Aleksandr D. Vakhrushev, Elena G. Koshevaya, Yury A. Skorik, Lubov B. Mitrofanova, Lada A. Murashova, Lev E. Korobchenko, Elizaveta M. Andreeva, Dmitry S. Lebedev, Olga M. Moiseeva and Evgeny N. Mikhaylov*

\begin{abstract}
Background: Mechanisms of positive effects of pulmonary artery (PA) denervation (PADN) remain poorly understood. The study aimed to evaluate pulmonary hemodynamic changes after PADN and their association with the extent of PA wall damage in an acute thromboxane A2 (TXA2)-induced pulmonary hypertension (PH) model in swine. Methods: In this experimental sham-controlled study, 17 normotensive male white Landrace pigs (the mean weight $36.2 \pm 4.5 \mathrm{~kg})$ were included and randomly assigned to group I $(n=9)$ - PH modeling before and after PADN, group II $(n=4)$-PADN only, or group III $(n=4)$ - PH modeling before and after a sham procedure. Radiofrequency (RF) PADN was performed in the PA trunk and at the proximal parts of the right and left PAs. PA wall lesions were characterized at the autopsy study using histological and the immunohistochemical examination.
\end{abstract}

Results: In groups I and II, no statistically significant changes in the mean pulmonary arterial pressure nor systemic blood pressure were found after PADN $(-0.8 \pm 3.4$ vs $4.3 \pm 8.6 \mathrm{mmHg}, P=0.47$; and $6.0 \pm 15.9$ vs $-8.3 \pm 7.5 \mathrm{mmHg}$, $P=0.1$; correspondingly). There was a trend towards a lower diastolic pulmonary arterial pressure after PADN in group I when compared with group III during repeat PH induction ( $34.4 \pm 2.9$ vs $38.0 \pm 0.8 ; P=0.06$ ). Despite the presence of severe PA wall damage at the RF application sites, S100 expression was preserved in the majority of PA specimens. The presence of high-grade PA lesions was associated with HR acceleration after PADN $(\rho=0.68, p=0.03)$. No significant correlation was found between the grade of PA lesion severity and PA pressure after PADN with or without PH induction.

Conclusions: Extended PADN does not affect PH induction using TXA2. Significant PA adventitia damage is associated with HR acceleration after PADN. Possible delayed effects of PADN on perivascular nerves and pulmonary hemodynamics require further research in chronic experiments.

Keywords: Pulmonary hypertension, Pulmonary denervation, Radiofrequency ablation, Large animal models, Synthetic analogue of thromboxane $A_{2}$

*Correspondence: ns.goncharova@gmail.com; e.mikhaylov@almazovcentre. ru

Almazov National Medical Research Centre, 2, Akkuratova Str., Saint-Petersburg, Russian Federation 197341

\section{Background}

The destruction of the neural elements in the pulmonary artery (PA) trunk and proximal parts of the right and left PAs is thought to abolish or significantly 
decrease the efferent sympathetic nervous supply of pulmonary vasculature and causes PA vasodilatation $[1,2]$. Several clinical studies have demonstrated a substantial improvement in pulmonary hemodynamics and exercise capacity after pulmonary artery denervation (PADN) in patients with different etiologies of pulmonary hypertension $(\mathrm{PH})$ [3-8], identifying interventional or surgical PADN as an attractive additional $\mathrm{PH}$ treatment option [9-13].

Large animals are used for the elaboration of the PADN technique and PA nerve lesion characteristics. However, hemodynamic effects should be interpreted with caution since acute models do not resemble chronic pulmonary arteries remodeling, and chronic models have different pathophysiology compared to humans [14]. The synthetic thromboxane A2 analogueinduced $\mathrm{PH}$ model suggests acute and dose-dependent PA pressure (PAP) elevation with complete PAP normalization after thromboxane A2 (TXA2) withdrawal $[15,16]$. Acute stable controlled but reversible TXA2induced $\mathrm{PH}$ could be a relevant type of $\mathrm{PH}$ modeling for acute PADN effects assessment.

Another limitation of in vivo studies is the lack of data on the association between the denervated PA surface area and the hemodynamic effects. Previous studies have reported on the limited possibility of transcatheter approaches for achieving deep PA lesions that result in perivascular nerve damage [17]. However, a recent study reported on acute radiofrequency (RF) PADN effects in swine with $\mathrm{PH}$ induced with a synthetic TXA2 analogue [18]. Rothman and co-workers have demonstrated that transcutaneous RF PADN in swine led to nerve fibers' damage with the absence of S100 expression at the sites of RF ablation, accompanied by a mean pulmonary artery pressure (mPAP) decrease in TXA2-induced $\mathrm{PH}$ modeling. However, the number of RF applications was small (from 2 to 7 lesions per animal) and did not lead to circumferential PA wall damage, while the authors demonstrated a correlation between the number of RF ablation and the mPAP decrease.

It is still unclear what radiofrequency (RF) ablation parameters might result in an effective PAP decrease, the quantity and timing of the PA neural damage for the treatment goal need further evaluation. We have hypothesized that the ablated PA wall area during PADN might be important for the resulting mPAP decrease in the TXA2-induced PH model.

The study aimed at the evaluation of pulmonary hemodynamic changes after PADN and their association with the extent of PA wall damage in an acute TXA2-induced PH model in swine.

\section{Methods}

\section{Experimental animals and study design}

The experimental study comprised 17 normotensive male white Landrace pigs. All procedures and protocols were reviewed and approved by the Institutional Animal Care and Use Committee and performed in the Preclinical and Translational Research Center of the Almazov National Medical Research Centre. The animals were obtained commercially from the CJSC "Livestock farm Ruchyi" (Saint-Petersburg, Russia) and were allowed enough time to habituate prior to procedures. The study was reported in accordance with ARRIVE guidelines https://arriveguid elines.org.

According to the study aim, we evaluated possible pulmonary hemodynamic changes in three different animal groups: induced $\mathrm{PH}$ before and after PADN (group I, PH-PADN), before and after PADN without PH induction (group II, nonPH-PADN), repeated $\mathrm{PH}$ induction with sham PADN (group III, PH-shamPADN). All animals were randomly assigned in one of three groups in the 2:1:1 ratio: group $I, n=9$; group $I I, n=4$; and group III, $n=4$. The size of the group I animals was chosen based on previous research [16]. We hypothesized that $\mathrm{PH}$ induction together with endothelial lesion during RF ablation may result in complications and hemodynamic deterioration in a part of study subjects. On the other hand, the requirement on minimizing the total number of large animals for experimental procedures forced us to limit two control groups-group II and III. Thus, the size of the group I would be justifiable larger than other groups. Blocked randomization was performed using an online randomization service (https://www.sealedenve lope.com/simple-randomiser/v1/lists). Randomization allocation was revealed to researchers at the moment the procedure started. However, further autopsy study was performed by pathologists (EGK and LBM) blinded to allocation groups.

In group I (PH-PADN), the protocol consisted of the following phases: (1) baseline hemodynamic assessment with right heart catheterization ( $\mathrm{RHC}$ ), (2) reversible $\mathrm{PH}$ modeling-1 using TXA2 infusion, (3) transcatheter radiofrequency PADN, (4) hemodynamic measurements with RHC, (5) reversible PH modeling-2, (6) euthanasia, (7) pathology and immunohistochemistry studies of the PA (Fig. 1).

In group II (nonPH-PADN), the protocol consisted of (1) baseline hemodynamic measurements with RHC, (2) PADN, (3) repeat hemodynamic assessment with RHC, (4) euthanasia, (5) pathology and immunohistochemistry studies of the PA.

The following phases were considered in group III (PHshamPADN): (1) baseline hemodynamic measurements with RHC, (2) reversible PH modeling-1, (3) a $60 \mathrm{~min}$ 


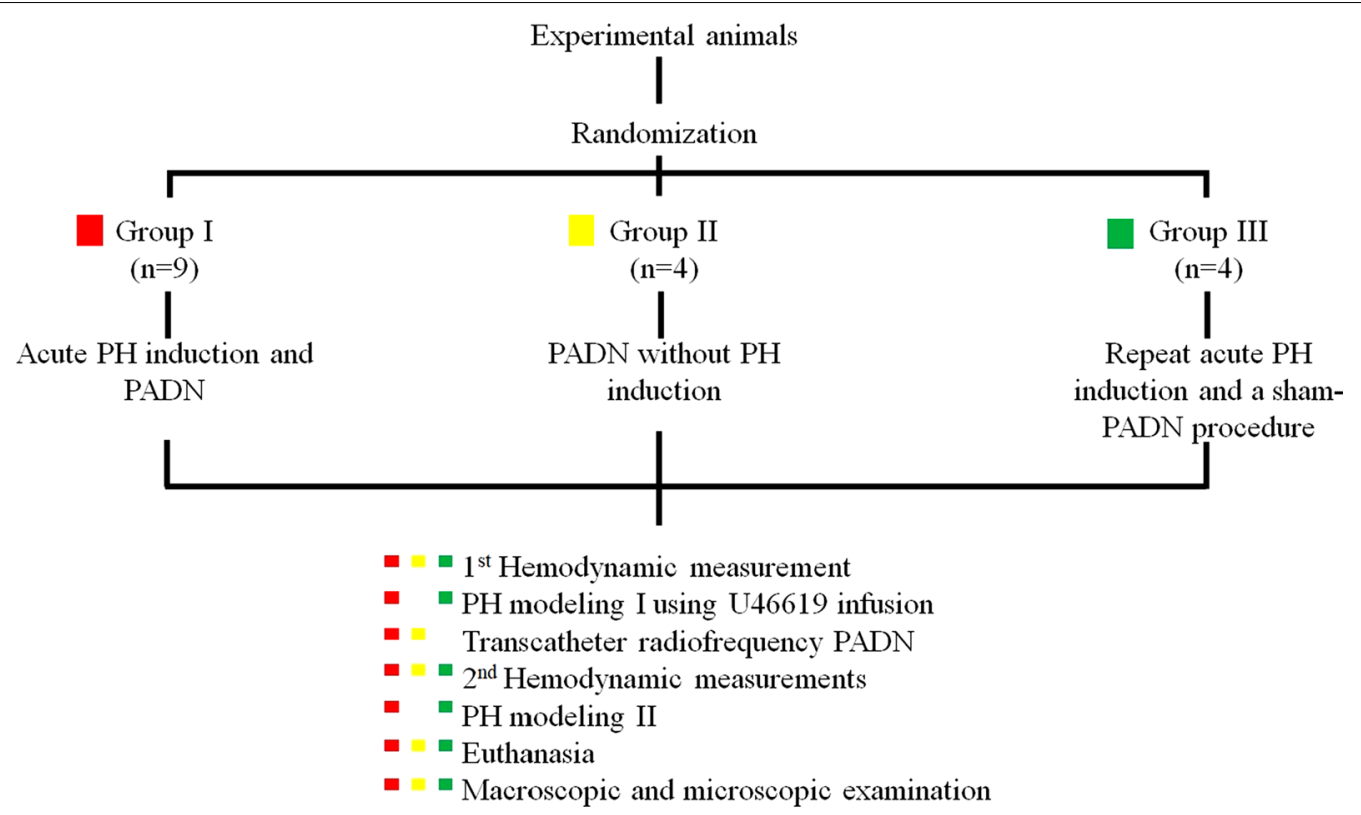

Fig. 1 Study flowchart. RHC -right heart catheterization; PH-modeling-1_-pulmonary hypertension induction using continuous TXA2 infusion before PADN; PH-modeling-2 - pulmonary hypertension induction using continuous TXA2 infusion after PADN; PADN-pulmonary artery denervation; mPAP_-mean pulmonary artery pressure

waiting period after hemodynamic normalization with catheter manipulations inside the PA and its branches, and RHC, (4) reversible PH modeling-2, (5) euthanasia, (6) autopsy study with PA pathology analyses.

\section{Experimental procedures Catheterization and hemodynamic evaluation}

The procedures were performed in a supine position under general anesthesia (tiletamine and zolazepam, $20 \mathrm{mg} / \mathrm{kg}$, xylazine $3 \mathrm{mg} / \mathrm{kg}$ and atropine $0.1 \mathrm{mg} / \mathrm{kg}$ for induction, and isoflurane, 2 to $3 \%$, with $\mathrm{O}_{2}$ via an endotracheal tube at $65 \%$ ), and vascular access was obtained via the right and left jugular veins and right external carotid artery. A 7F vascular sheath (AVANTI ${ }^{\circledR}+$, Cordis, Florida, USA) was placed into the right internal jugular vein. PA angiography was performed using a multipurpose angiographic catheter (Multipurpose, Cordis, USA) using a fluoroscopic C-arm (BV Endura C-Arm, Philips, Veenpluis, The Netherlands). RHC with the assessment of systolic pulmonary artery pressure (PAP), diastolic PAP, mPAP, mean right atrial pressure (mRAP), and pulmonary capillary wedge pressure (PCWP) was performed using the Swan Ganz catheter (Corodyn ${ }^{\mathrm{TM}} \mathrm{P} 2$, BRAUN, Bethlehem, Germany). Systemic BP was monitored and arterial blood samples were taken from the right external carotid artery. Arterial and PA blood gas analyses were performed using the I-STAT analyzer (Abbot, USA). Cardiac output $(\mathrm{CO})$ was determined using the Fick method; pulmonary vascular resistance (PVR) and systemic vascular resistance (SVR) were calculated per the established equation formula $(\mathrm{PVR}=[80 \times(\mathrm{mPAP}-\mathrm{PCWP}) / \mathrm{CO}])$. Hemodynamic measurements and monitoring were initiated after vascular sheaths placements and were continued throughout the procedure. Discrete measurements at baseline, at target mPAP during PH modeling-1, $20 \mathrm{~min}$ after PADN, and target mPAP during $\mathrm{PH}$ modeling-2 were performed. To prevent thrombotic complications, heparin sulfate was administered intravenously at a rate of $300 \mathrm{U} / \mathrm{kg} / \mathrm{h}$ with the target ACT $>300 \mathrm{~s}$. To maintain intravascular volume, an isotonic $\mathrm{NaCl}$ solution and succinylated gelatin (Gelosfusine ${ }^{\circledR}$, Braun, Germany) were administered continuously; body temperature was maintained at $38{ }^{\circ} \mathrm{C}$ using a warming system (WarmTouch ${ }^{\mathrm{TM}}$, Medtronic, MN, USA).

\section{Pulmonary artery denervation procedure}

Recurrent and phrenic nerves damage during PADN was prevented by PA stimulation mapping before each RF application as described previously [19]. Mapping and ablation were performed using a $3.5-\mathrm{mm}$ tip openirrigated ablation catheter (Celsius THERMOCOOL, Biosense Webster, CA, USA) under the guidance of the Biotok Unity electrophysiology and electroanatomic navigation system (Biotok, Tomsk, Russia); detailed technical aspects of the procedure were described elsewhere $[19,20]$. RF ablation (40 W; application duration 
$30 \mathrm{~s}$; irrigation $30 \mathrm{ml} / \mathrm{min}$; RF power generator Biotok or ATAKR ${ }^{\circledR}$ II RF, Medtronic, MN, USA) was performed in the PA trunk and proximal parts of the right and left PAs with the intention of circumferential ablations (excluding the sites with phrenic and recurrent laryngeal nerve capture while pacing; Fig. 2). In group I (PH-PADN), the PADN procedure was performed after a 20-min waiting period following complete restoration of mPAP to the baseline value after PH modeling-1.

\section{PH modeling with TXA2}

The target mPAP during $\mathrm{PH}$ modeling was $40 \mathrm{mmHg}$. $\mathrm{PH}$ was induced with continuous infusion of TXA2 $(10 \mathrm{mg} /$ $\mathrm{ml}$; Tocris, Bristol, UK) through the left external jugular vein. The dose titration of the synthetic TXA2 analogue (U46619) was individual and adjusted in every animal. The dosage was increased gradually every $5 \mathrm{~min}$ in accordance with a predefined protocol $(0.025,0.05$, $\left.0.075,0.1,0.12,0.15,0.175 \mu \mathrm{g}^{*} \mathrm{~kg}^{-1 *} \min ^{-1}\right)$ until the target mPAP [16]. Reversible PH modeling-1 was conducted after baseline hemodynamic assessment and reversible $\mathrm{PH}$ modeling-2 was performed $20 \mathrm{~min}$ after the PADN procedure. The dosage of TXA2 needed for the target mPAP was assessed before and after PADN in each animal. In group III (PH-shamPADN), PH modeling was conducted twice: the time difference between

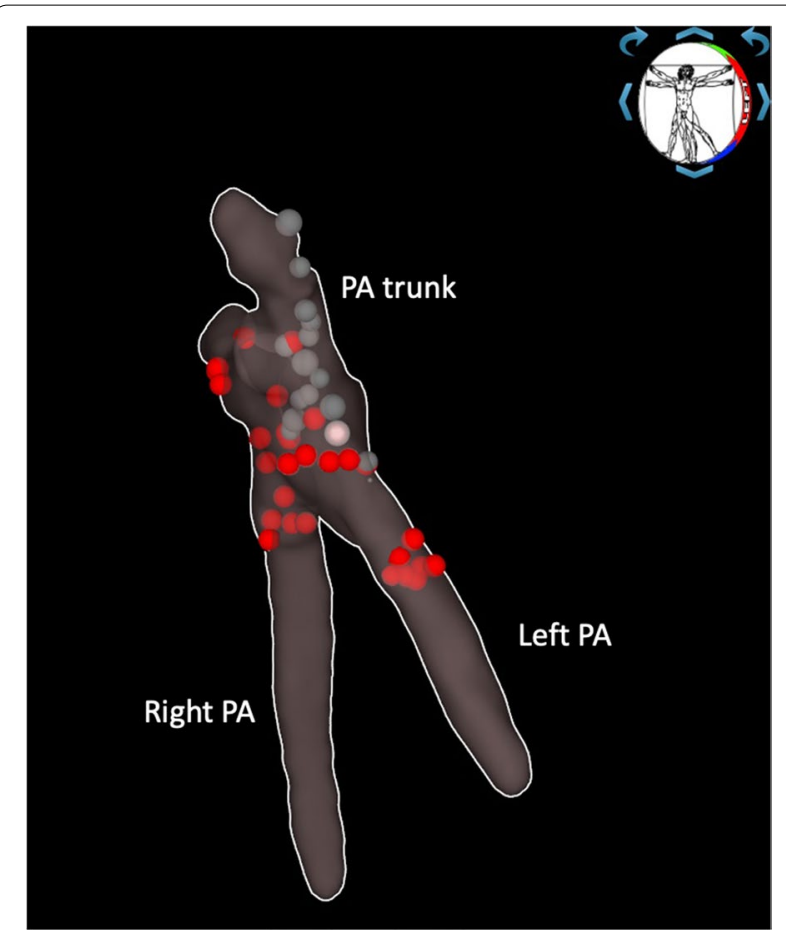

Fig. 2 Three-dimensional electroanatomic map of the pulmonary artery with stimulation points where phrenic nerve was captured (gray points) and RF ablation points (red points)
$\mathrm{PH}$ modeling- 1 and 2 was 60 min to reproduce the time required for PADN in groups I and II.

\section{Autopsy study and histological and immunohistochemical examination}

After the experimental procedures, all animals were euthanized with an intracardiac injection of a lethal dose of potassium chloride. The heart and lungs were excised en bloc for gross anatomy assessment and histological examination of the PA trunk, left, and right PAs, and lungs at ablation sites. PA and its branches were transversely sampled into rings with a $5-\mathrm{mm}$ step, and the samples were fixed in $10 \%$ buffered formalin, microscopy items were prepared routinely and stained with hematoxylin and eosin. Mallory trichrome staining (Biovitrum, Russia) was used to assess adventitia and perivascular adipose tissue in the areas of PA ablation. Immunohistochemical labeling was performed with antibodies for S100 protein (Dako Cytomation, Denmark) to detect nerve fibers as previously described [21]. The Leica Application Suite V 4.5.0 image analyzer and Leica Scope (Leica, Germany) were used for morphometric analysis. At the sites of identified RF lesions, the pulmonary artery was cut into rings (width $1 \mathrm{~cm}$ ) which included a non-damaged area around the lesions. Each detected lesion was classified into grades I, II or III according to a previously published description [22]. The percentage of RF-induced lesions was calculated according to the following description: the area of a PA lesion divided by the total area of a PA ring specimen ${ }^{*} 100 \%$. The percentage of a lesion was calculated separately for each lesion grade.

\section{Statistical analysis}

Hemodynamic parameters (heart tare [HR], mBP, mPAP, RAP, PCWP, CO, PVR, and SVR) were analyzed to determine changes from the baseline and after PADN, between the PH modeling- 1 and PH modeling-2. The TXA2 dosage and time to the target mPAP were compared during PH modeling- 1 and 2 and after PADN. RF-induced PA lesions were presented as the percentage of the injured area. The association between the hemodynamic changes after PADN, in PH modeling-2 and the characteristics of RF-induced PA lesions were investigated. Data are presented as mean \pm standard deviation $(\mathrm{M} \pm \mathrm{SD})$, absolute numbers and percentages. Mean values were compared using the Mann-Whitney U-test, Wilcoxon signed-rank test and Kruskal-Wallis ANOVA tests, as appropriate. Correlations were evaluated using the Spearman test. A statistically significant difference was determined as a two-tailed $P<0.05$. Statistical analysis of the data was carried out using Statistica for Windows, version 10.0 (StatSoft, USA). 


\section{Results}

The mean bodyweight of the animals was $36.2 \pm 4.5 \mathrm{~kg}$ (age about 3 months). Baseline hemodynamic parameters are presented in Table 1. In two groups of animals where $\mathrm{RF}$ ablation was performed, the average number of ablation points was $23 \pm 10$.

\section{Pulmonary artery denervation in group I (PH-PADN)}

Hemodynamic parameters at baseline, and during $\mathrm{PH}$ induction-1 and $\mathrm{PH}$-induction-2 are presented in Additional file 1: Table S1. TXA2 infusion was characterized by a dose-dependent target mPAP elevation due to significant PVR increase and accompanied with $\mathrm{CO}$ reduction. After reversible $\mathrm{PH}$ modeling-1 and subsequent pulmonary hemodynamics normalization, PADN was performed. The mean number of RF applications in the PA was trunk was $28.7 \pm 16.5$, in the right PA $8.6 \pm 6.0$, and in the left PA $8.2 \pm 4.8$.

The full study protocol with hemodynamic measurements was completed in 5 out of 9 animals. In three cases, pulmonary embolism (PE) was encountered: in animals \#1 and 4 at the completion of the study protocol; in animal \#6, PE was diagnosed and confirmed angiographically immediately after PADN, PH modeling-2 was not performed. In pigs \#1 and 4 with PE, $\mathrm{PH}$ modeling- 2 was characterized by lower doses of TXA2 and hemodynamic instability with profound blood pressure loss (Additional file 1: Table S1). In pig \#8, TXA2 infusion was stopped during $\mathrm{PH}$ modeling-2 due to ventricular fibrillation and the data for PH modeling- 2 in pig \#8 as well as for animals with PE were removed from the analyses. No structural cardiac abnormality or PE was found in pig \#8 on the autopsy study. Therefore, hemodynamic analysis after PADN in group I was performed on data obtained from 6 pigs, and hemodynamic data on $\mathrm{PH}$ modeling- 2 was analyzed on 5 animals. Stable reversible $\mathrm{PH}$ modeling-2 was reproducible in all 5 animals and after TXA2 infusion termination, mPAP returned to its initial values within 15-20 min in all analyzed cases. The mean dose of TXA2 for the second PH induction was comparable to that used for the first induction.

\section{Pulmonary artery denervation in group II (nonPH-PADN)}

The mean number of RF applications was $21.3 \pm 0.5$ and the number of RF applications in PA trunk $(8.3 \pm 0.9)$, left $(6.5 \pm 0.9)$ and right PAs $(6.5 \pm 0.9)$ was comparable to group I ( $p=0.4 ; p=0.2 ; p=0.6 ; p=0.4$, respectively; Table 2). There was no PE in group II, and data from all 4 animals were included in analyses. No pulmonary nor systemic hemodynamic changes were noted after PADN in this normotensive group.

\section{Pulmonary hypertension modeling in group III (PH-shamPADN)}

The target mPAP was achieved in all animals in group III $(\mathrm{n}=4)$ and no signs of PE were detected. PH-modeling-2 was characterized by the same TXA2 doses and infusion time as the first $\mathrm{PH}$ modeling. The hemodynamic parameters between $\mathrm{PH}$ modeling- 1 and -2 had no difference (Table 3). Therefore, there was no statistically detectable delayed effect of TXA2 on PVR or SVR during PH modeling-2.

Table 1 Baseline hemodynamic characteristics of the three groups (Kruskal-Wallis ANOVA, mean \pm SD)

\begin{tabular}{|c|c|c|c|c|c|}
\hline Parameters & All pigs, $n=17$ & Group I (PH-PADN), $\mathrm{n}=\mathbf{9}$ & $\begin{array}{l}\text { Group II (non } \\
\text { PH-PADN), } n=4\end{array}$ & $\begin{array}{l}\text { Group III } \\
\text { (PH-shamPADN) } n=4\end{array}$ & $p$ value \\
\hline $\mathrm{HR}$, beat/min & $97.5 \pm 15.4$ & $96.9 \pm 11.0$ & $97.8 \pm 29.2$ & $98.8 \pm 9.1$ & 0.86 \\
\hline $\mathrm{SBP}, \mathrm{mmHg}$ & $94.0 \pm 11.5$ & $93.1 \pm 10.3$ & $90.3 \pm 12.6$ & $99.8 \pm 13.7$ & 0.47 \\
\hline DBP, mmHg & $54.0 \pm 7.7$ & $55.9 \pm 5.8$ & $50.5 \pm 3.1$ & $53.3 \pm 13.7$ & 0.21 \\
\hline $\mathrm{mBP}, \mathrm{mm} \mathrm{Hg}$ & $66.8 \pm 9.2$ & $67.1 \pm 8.5$ & $64.3 \pm 6.4$ & $68.8 \pm 14.3$ & 0.80 \\
\hline SPAP, mm Hg & $16.8 \pm 3.9$ & $17.2 \pm 4.5$ & $15.3 \pm 3.3$ & $17.3 \pm 2.6$ & 0.52 \\
\hline DPAP, $\mathrm{mm} \mathrm{Hg}$ & $12.0 \pm 3.5$ & $12.4 \pm 3.8$ & $10.3 \pm 1.7$ & $12.8 \pm 4.3$ & 0.58 \\
\hline mPAP, $\mathrm{mm} \mathrm{Hg}$ & $13.5 \pm 3.7$ & $13.9 \pm 4.0$ & $11.8 \pm 2.5$ & $14.5 \pm 4.0$ & 0.54 \\
\hline $\mathrm{RAP}, \mathrm{mm} \mathrm{Hg}$ & $3.5 \pm 2.2$ & $3.9 \pm 2.0$ & $2.3 \pm 1.5$ & $4.0 \pm 3.2$ & 0.36 \\
\hline PCWP, mm Hg & $4.4 \pm 1.8$ & $4.4 \pm 2.1$ & $3.8 \pm 1.3$ & $4.8 \pm 1.7$ & 0.74 \\
\hline $\mathrm{CO}, \mathrm{l} / \mathrm{min}$ & $4.5 \pm 1.5$ & $4.7 \pm 1.8$ & $5.1 \pm 1.3$ & $3.4 \pm 0.7$ & 0.21 \\
\hline$P V R$, dyn/s/sm ${ }^{-5}$ & $186.6 \pm 94.4$ & $181.7 \pm 85.4$ & $139.7 \pm 73.8$ & $244.8 \pm 122.8$ & 0.37 \\
\hline SVR, dyn/s/sm ${ }^{-5}$ & $1252.7 \pm 419.2$ & $1213.0 \pm 455.6$ & $1018.0 \pm 240.2$ & $1576.5 \pm 328.9$ & 0.19 \\
\hline
\end{tabular}

PH_pulmonary hypertension; PADN_-pulmonary artery denervation; HR_heart rate; SBP_systolic blood pressure; DBP_diastolic blood pressure; mBP_-mean arterial pressure; SPAP_systolic pulmonary arterial pressure; DPAP_diastolic pulmonary arterial pressure; mPAP_mean pulmonary artery pressure; RAP_right atrial pressure; PCWP—-pulmonary capillary wedge pressure; CO—cardiac output; PVR—pulmonary vascular resistance; SVR—systemic vascular resistance 
Table 2 Hemodynamic data after PADN during the normotensive period without the phase of PH induction in groups I (PH-PADN) and II (non-PH-PADN), (mean \pm SD)

\begin{tabular}{|c|c|c|c|c|c|c|}
\hline \multirow[t]{2}{*}{ Parameters } & \multirow[t]{2}{*}{$\begin{array}{l}\text { Group I (PH-PADN) } \\
\mathrm{n}=6\end{array}$} & \multirow[t]{2}{*}{$\begin{array}{l}\text { Group II (nonPH- } \\
\text { PADN) } n=4\end{array}$} & \multirow[t]{2}{*}{$p$ value* } & \multicolumn{2}{|c|}{$\begin{array}{l}\text { Difference between baseline and after } \\
\text { PADN }\end{array}$} & \multirow[t]{2}{*}{$P$ valuet } \\
\hline & & & & $\begin{array}{l}\text { Group (PH-PADN), } \\
n=6\end{array}$ & $\begin{array}{l}\text { Group II (nonPH- } \\
\text { PADN), } n=4\end{array}$ & \\
\hline Weight, kg & $35.7 \pm 2.6$ & $39.5 \pm 3.1$ & 0.06 & - & - & - \\
\hline Ablation number & $28.7 \pm 16.5$ & $21.3 \pm 0.5$ & 0.4 & - & - & - \\
\hline PA trunk ablation number & $12.0 \pm 6.1$ & $8.3 \pm 0.9$ & 0.2 & - & - & - \\
\hline Left PA, ablation number & $8.2 \pm 6.0$ & $6.5 \pm 0.6$ & 0.6 & - & - & - \\
\hline Right PA, ablation number & $8.6 \pm 4.8$ & $6.5 \pm 0.6$ & 0.4 & - & - & - \\
\hline $\mathrm{HR}$, beats/min & $104.7 \pm 17.2$ & $95.0 \pm 13.7$ & 0.35 & $10.3 \pm 20.5$ & $-2.7 \pm 15.6$ & 0.46 \\
\hline $\mathrm{SBP}, \mathrm{mmHg}$ & $96.3 \pm 7.7$ & $83.5 \pm 8.3$ & 0.038 & $0.5 \pm 16.3$ & $-6.8 \pm 8.8$ & 0.26 \\
\hline $\mathrm{DBP}, \mathrm{mmHg}$ & $62.8 \pm 11.1$ & $42.0 \pm 5.0$ & 0.066 & $6.2 \pm 13.9$ & $-8.5 \pm 6.9$ & 0.06 \\
\hline $\mathrm{mBP}, \mathrm{mm} \mathrm{Hg}$ & $74.0 \pm 9.5$ & $56.0 \pm 4.3$ & 0.066 & $6.0 \pm 15.9$ & $-8.3 \pm 7.5$ & 0.1 \\
\hline SPAP, mm Hg & $18.7 \pm 4.8$ & $19.0 \pm 8.8$ & 0.61 & $-0.0 \pm 3.0$ & $3.8 \pm 10.4$ & 0.91 \\
\hline DPAP, mm Hg & $11.8 \pm 4.6$ & $14.8 \pm 7.6$ & 0.47 & $-1.7 \pm 3.9$ & $4.5 \pm 7.8$ & 0.26 \\
\hline mPAP, mm Hg & $14.2 \pm 4.4$ & $16.0 \pm 8.1$ & 0.91 & $-0.8 \pm 3.4$ & $4.3 \pm 8.6$ & 0.47 \\
\hline mRAP, mm Hg & $3.5 \pm 3.0$ & $5.0 \pm 4.2$ & 0.47 & $-0.3 \pm 3.7$ & $2.8 \pm 4.5$ & 0.26 \\
\hline PCWP, mm Hg & $4.0 \pm 1.7$ & $5.0 \pm 3.4$ & 0.91 & $-0.0 \pm 2.3$ & $1.3 \pm 3.6$ & 0.76 \\
\hline $\mathrm{CO}, \mathrm{I} / \mathrm{min}$ & $4,6 \pm 1,9$ & $5.5 \pm 1.7$ & 0.61 & $-0.2 \pm 1.1$ & $0.4 \pm 1,8$ & 0.61 \\
\hline PVR, dyn $/ \mathrm{s} / \mathrm{sm}^{-5}$ & $214.8 \pm 138.2$ & $177.5 \pm 102.8$ & 0.76 & $14.1 \pm 61.5$ & $37.8 \pm 125.0$ & 1 \\
\hline SVR, dyn $/ \mathrm{s} / \mathrm{sm}^{-5}$ & $1474.6 \pm 755.9$ & $779.2 \pm 141.1$ & 0.17 & $318.9 \pm 399.7$ & $-238.8 \pm 244.7$ & 0.038 \\
\hline
\end{tabular}

$\mathrm{PH}$ —pulmonary hypertension; PADN—pulmonary artery denervation; HR—heart rate; SBP—systolic blood pressure; DBP—diastolic blood pressure; mBP—-mean arterial pressure; SPAP -systolic pulmonary arterial pressure; DPAP—diastolic pulmonary arterial pressure; mPAP—-mean pulmonary artery pressure; RAP- right atrial pressure; PCWP—-pulmonary capillary wedge pressure; CO—cardiac output; PVR—pulmonary vascular resistance; SVR—systemic vascular resistance

* Mann-Whitney $\mathrm{U}$ two-sided exact test; + Wilcoxon signed-rank test

Pulmonary artery denervation and hemodynamics during normotensive periods in groups I (PH-PADN) and II (nonPH-PADN)

There was no statistically significant change in pulmonary pressures, and $\mathrm{CO}$ immediately after PADN in the entire cohort of pigs with PADN $(n=10)$; as well as in separate analyses within groups I and II (Table 2).

At the same time, there was a significant SBP $(p=0.036)$ drop and a trend toward lower DBP and mBP $(p=0.06 ; p=0.06$, respectively) in group II (nonPHPADN) compared to group I (PH-PADN) immediately after PADN (Fig. 3). The differences between DBP and SVR at the baseline and following PADN were significant in group II (nonPH-PADN) (Table 2).

No meaningful correlations were found between the number of RF applications in PA and pressure values after PADN in the all PADN pigs (mBP: $\rho=0.031$; SPAP: $\rho=0.376$; DPAP: $\rho=0.22$; mPAP: $\rho=0.36$; PCWP: $\rho=-0.23$; RAP: $\rho=0.28$; CO: $\rho=-0.32$; SVR: $\rho=0.10$; PVR: $\rho=0.42 ; p>0.05$ for all parameters). However, in group I (PH-PADN), positive correlations were noted between the number of RF ablations and HR, SPAP and RAP immediately after PADN $(\rho=0.82, p=0.02$; $\rho=0.67, p=0.02 ; \rho=0.62, p=0.049$, respectively), as well as a PVR difference between baseline and after $\operatorname{PADN}(\rho=0.64, p=0.02$, Additional file 1: Figure S1). No significant correlations between the number of RF applications and hemodynamic parameters were noted in group II (nonPH-PADN).

\section{Pulmonary arterial hypertension modeling-2 in group I (PH-PADN) and group III (PH-shamPADN)}

The TXA2 dose and the time to the target mPAP in $\mathrm{PH}$ modeling-1 and 2 did not differ between groups I (PH-PADN) and III (PH-shamPADN): $20.1 \pm 7.1$ vs $24.5 \pm 5.7 \mu \mathrm{g} / \mathrm{kg}, P=0.35 ; 18.3 \pm 8.8 \mathrm{Vs} 16.3 \pm 9.5 \mathrm{~min}$, $P=0.61$, respectively. Within each group, there was no change in a consumed TXA2 dose for the second $\mathrm{PH}$ modeling (Table 3). At PH modeling-1, the PCWP was higher in group III (PH-shamPADN) than in group I (PH-PADN): $7.0 \pm 1.8$ vs $4.3 \pm 0.8 \mathrm{~mm} \mathrm{Hg}, P=0.02$. Diastolic PAP tended to decrease after PADN during PH modeling-2 $(p=0.06)$ when compared with the PH-shamPADN group (Fig. 4). In group III (PH-shamPADN), PH modeling-2 was characterized by a higher RAP difference between the $\mathrm{PH}$ modeling-1 and -2 
Table 3 Hemodynamic data and the TXA2 dosage on PH modeling-2 in group I (PH-PADN) and group III (PH-shamPADN) (mean \pm SD)

\begin{tabular}{|c|c|c|c|c|c|c|}
\hline \multirow[t]{2}{*}{ Parameters } & \multirow[t]{2}{*}{$\begin{array}{l}\text { Group I (PH-PADN), } \\
\mathrm{n}=6\end{array}$} & \multirow[t]{2}{*}{$\begin{array}{l}\text { Group III (PH-shamPADN), } \\
\mathrm{n}=4\end{array}$} & \multirow[t]{2}{*}{$p$ value $*$} & \multicolumn{2}{|c|}{$\begin{array}{l}\text { Difference between PH } 1 \text { and PH } 2 \\
\text { modeling }\end{array}$} & \multirow[t]{2}{*}{$P$ value $^{\dagger}$} \\
\hline & & & & $\begin{array}{l}\text { Group I } \\
\text { (PH-PADN), } n=6\end{array}$ & $\begin{array}{l}\text { Group III } \\
\text { (PH-shamPADN), } \\
n=4\end{array}$ & \\
\hline Weight, kg & $35.7 \pm 2.6$ & $39.2 \pm 1.9$ & 0.038 & & & \\
\hline TXA2 dose, $\mu \mathrm{g} / \mathrm{kg}$ for $\mathrm{PH} 1$ & $20.1 \pm 7.1$ & $24.5 \pm 5.7$ & 0.35 & $3.25 \pm 1.9$ & $3.26 \pm 8.3$ & 0.5 \\
\hline TXA2 dose, $\mu \mathrm{g} / \mathrm{kg}$ for $\mathrm{PH} 2$ & $18.9 \pm 6.7$ & $21.2 \pm 8.2$ & 0.9 & & & \\
\hline Time to target mPAP-1, min & $20.0 \pm 11.0$ & $18.8 \pm 6.3$ & 0.76 & $4 \pm 2.2$ & $2.5 \pm 10.4$ & 0.73 \\
\hline Time to target mPAP-2, min & $18.3 \pm 8.8$ & $16.3 \pm 9.5$ & 0.61 & & & \\
\hline $\mathrm{HR}$, beat/min & $117.6 \pm 20.6$ & $115.8 \pm 14.9$ & 0.9 & $2.2 \pm 10.6$ & $-5.5 \pm 16.5$ & 0.5 \\
\hline SBP, mmHg & $94.8 \pm 13.8$ & $104.0 \pm 36.5$ & 0.5 & $10.0 \pm 10.9$ & $-1.0 \pm 37.7$ & 0.5 \\
\hline $\mathrm{DBP}, \mathrm{mmHg}$ & $66.8 \pm 12.5$ & $62.3 \pm 24.3$ & 0.9 & $6.0 \pm 6.5$ & $-0.8 \pm 27.0$ & 0.7 \\
\hline $\mathrm{mBP}, \mathrm{mm} \mathrm{Hg}$ & $76.2 \pm 11.5$ & $76.0 \pm 27.9$ & 0.9 & $7.2 \pm 8.1$ & $-0.5 \pm 30.0$ & 0.7 \\
\hline SPAP, mm Hg & $44.6 \pm 5.0$ & $42.8 \pm 1.0$ & 0.28 & $1.2 \pm 4.3$ & $-1.5 \pm 3.1$ & 0.28 \\
\hline DPAP, mm Hg & $34.4 \pm 2.9$ & $38.0 \pm 0.8$ & 0.06 & $-1.2 \pm 1.8$ & $-1.0 \pm 1.4$ & 0.9 \\
\hline mPAP, mm Hg & $38.2 \pm 2.5$ & $39.8 \pm 0.5$ & 0.5 & $0.0 \pm 1.2$ & $-1.5 \pm 1.7$ & 0.2 \\
\hline mRAP, $\mathrm{mm} \mathrm{Hg}$ & $7.2 \pm 1.9$ & $5.3 \pm 2.2$ & 0.28 & $-2.2 \pm 1.6$ & $1.0 \pm 0.8$ & 0.015 \\
\hline PCWP, mm Hg & $5.6 \pm 0.6$ & $6.8 \pm 10$ & 0.11 & $-1.2 \pm 0.4$ & $0.3 \pm 1.3$ & 0.06 \\
\hline $\mathrm{CO}, \mathrm{l} / \mathrm{min}$ & $3.0 \pm 1.5$ & $2.4 \pm 0.7$ & 1 & $0.8 \pm 1.5$ & $0.3 \pm 1.4$ & 0.9 \\
\hline $\mathrm{PVR}, \mathrm{dyn} / \mathrm{s} / \mathrm{sm}^{-5}$ & $740.9 \pm 421.2$ & $1228.9 \pm 524.3$ & 0.4 & $-171.6 \pm 874.5$ & $107.7 \pm 798.2$ & 0.9 \\
\hline SVR, dyn $/ \mathrm{s} / \mathrm{sm}^{-5}$ & $2091.8 \pm 800.8$ & $2373.7 \pm 692.8$ & 0.7 & $10.0 \pm 623.1$ & $101.0 \pm 549.0$ & 0.9 \\
\hline
\end{tabular}

PH_pulmonary hypertension; PADN—pulmonary artery denervation; HR — heart rate; SBP—systolic blood pressure; DBP_diastolic blood pressure; mBP_-mean arterial pressure; SPAP -systolic pulmonary arterial pressure; DPAP—diastolic pulmonary arterial pressure; mPAP—-mean pulmonary artery pressure; RAP—right atrial pressure; PCWP_-pulmonary capillary wedge pressure; $C O$ —cardiac output; PVR—pulmonary vascular resistance; SVR—systemic vascular resistance

*Mann-Whitney U two-sided exact test

${ }^{\dagger}$ Wilcoxon signed-rank test

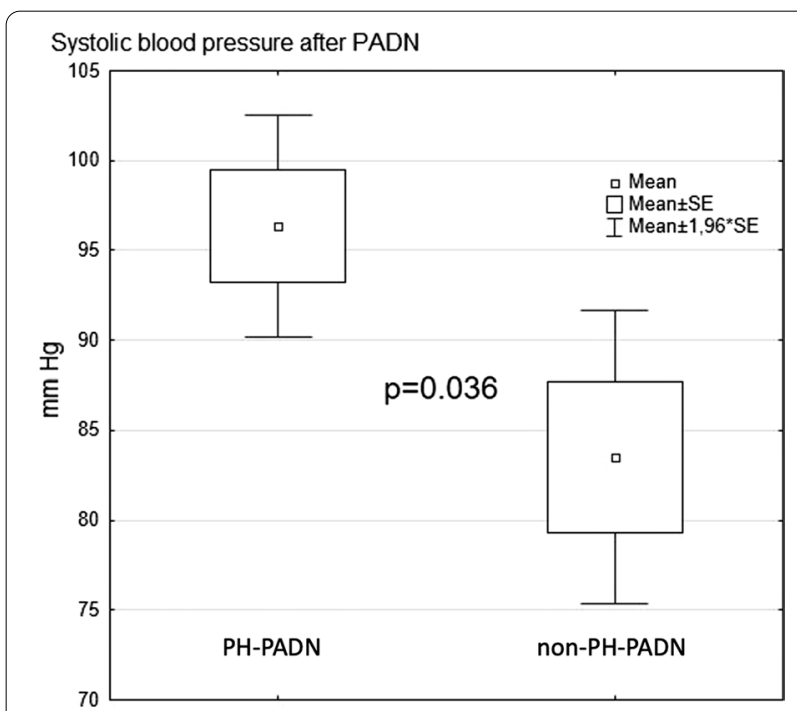

Fig. 3 Systolic BP decrease in group II (nonPH-PADN) after PADN

when compared with group I (PH-PADN), $(1.0 \pm 0.8 \mathrm{Vs}$ $-2.2 \pm 1.6 \mathrm{~mm} \mathrm{Hg}, P=0.015)$.

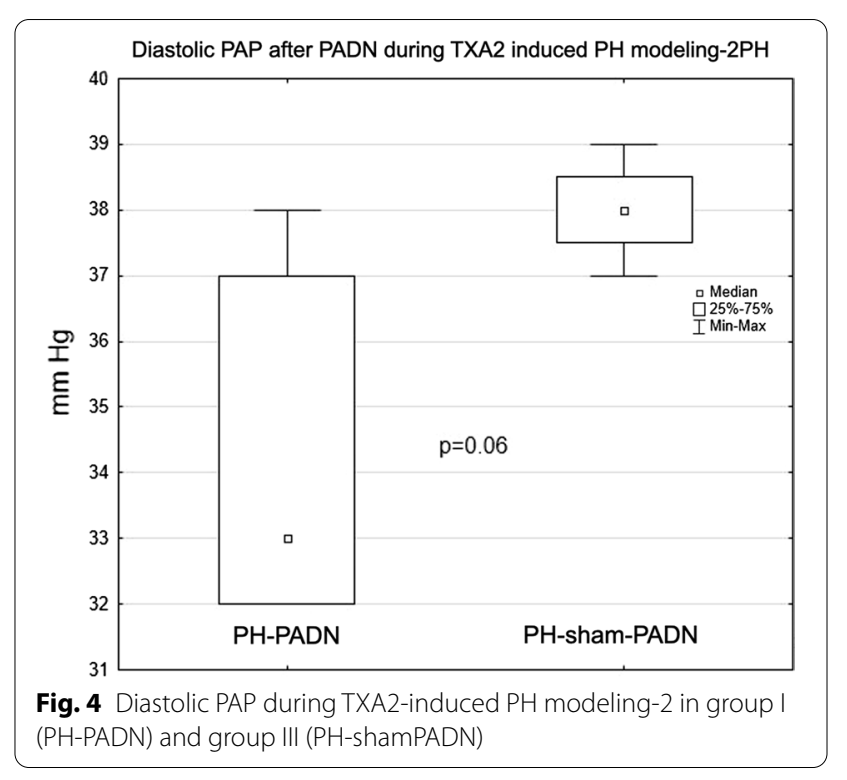

A positive correlation was observed between the number of RF applications and the HR during PH modeling-2 $(\rho=0.9 ; p=0.037)$. 


\section{Artery wall lesion severity and hemodynamic changes} after pulmonary artery denervation

The percentage of the area with grade I lesions was higher in group I (PH-PADN) when compared with group II (nonPH-PADN): $50 \pm 13.5$ vs $20.2 \pm 15.0 \%$; $P=0.038$ (Table 4). No significant correlation was

Table 4 Summary of the lesions percentage in group I and group II. (mean \pm SD)

\begin{tabular}{lcll}
\hline $\begin{array}{l}\text { Lesion grade } \\
\text { percentage (\%) }\end{array}$ & $\begin{array}{l}\text { Group I } \\
\text { (PH-PADN) }(\mathbf{n}=\mathbf{6})\end{array}$ & $\begin{array}{l}\text { Group II (nonPH- } \\
\text { PADN) }(\mathbf{n = 4 )}\end{array}$ & P value* \\
\hline All lesions & $94.3 \pm 49.8$ & $110 \pm 43.7$ & 0.61 \\
Grade I & $20 \pm 15$ & $50 \pm 13.5$ & 0.038 \\
Grade II & $25.8 \pm 8.6$ & $30 \pm 19$ & 0.61 \\
Grade III & $45.8 \pm 31.5$ & $40 \pm 8.7$ & 0.9 \\
Grade II+ III & $74 \pm 35.7$ & $60 \pm 34.8$ & 0.47 \\
\hline
\end{tabular}

*Mann-Whitney U two-sided exact test detected between the lesion percentages and hemodynamic changes after PADN in group II (nonPHPADN) (HR: $\rho=0.94$; SBP: $\rho=0.60$; DBP: $\rho=0.8$; $\mathrm{mBP}$ : $\rho=0.6$; SPAP: $\rho=-0.4$; DPAP: $\rho=0$; mPAP: $\rho=-0.21$; PCWP: $\rho=-0.40$; RAP: $\rho=-0.31$; CO: $\rho=0.40$; PVR: $\rho=-0.20$; SVR: $\rho=-0.20$, respectively; $p>0.05$ for all parameters).

In the animals after PADN (PH-PADN and nonPHPADN groups, $\mathrm{n}=10$ ), RF-induced PA lesions were inhomogeneous (Fig. 5), here fore, a semi-quantitative grading system for each detected RF lesion was applied (Additional file 1: Table S2) [22]. The percentages of the lesion grades are presented in Additional file 1: Table S3. S100 expression was preserved in the majority of the PA specimens with RF ablation, even in cases with the most severe adventitia lesions-grade III (Fig. 6). A strong positive correlation was evident between the type III lesion percentage in the PA and the number of RF applications $(\rho=0.74, p=0.013)$. A
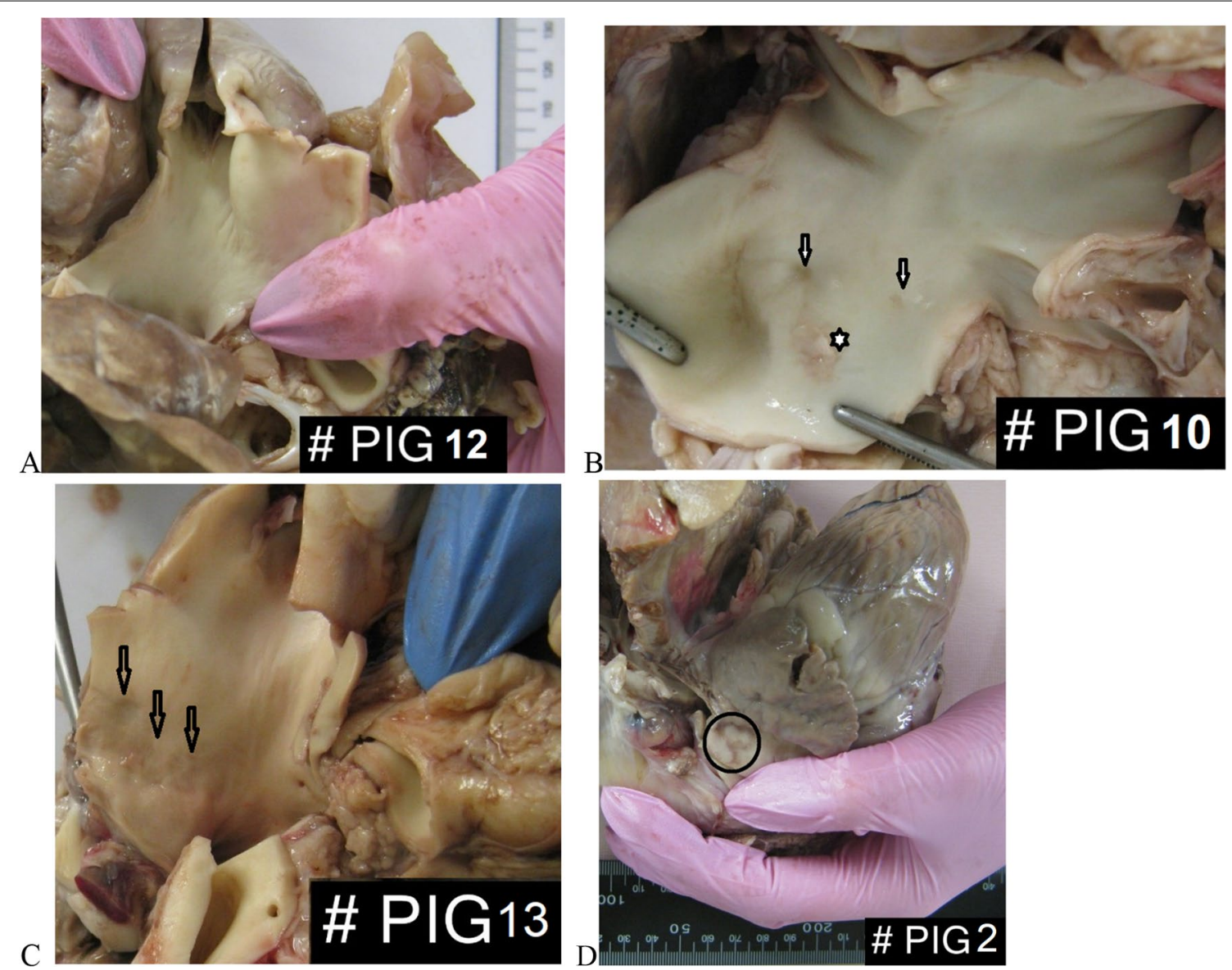

Fig. 5 Macroscopic evaluation of RF-induced PA lesions: a. No lesions observed in the PA trunk, left and right PAs; $\mathbf{b}$ and $\mathbf{c}$. Brown spots (arrows) depict PA wall hemorrhages and rough defects ( $4 \mathrm{~mm}-3 \mathrm{~mm}-2 \mathrm{~mm}$ in size); the asterisk corresponds to superficial dissection with intima detachment and media disorganization; d Macroscopic view of a RF-induced lesion at the PA trunk (circle) corresponds to coagulation necrosis of adventitia, perivascular fat and nerve fibers with intact underlying intima and media on further histological examination 


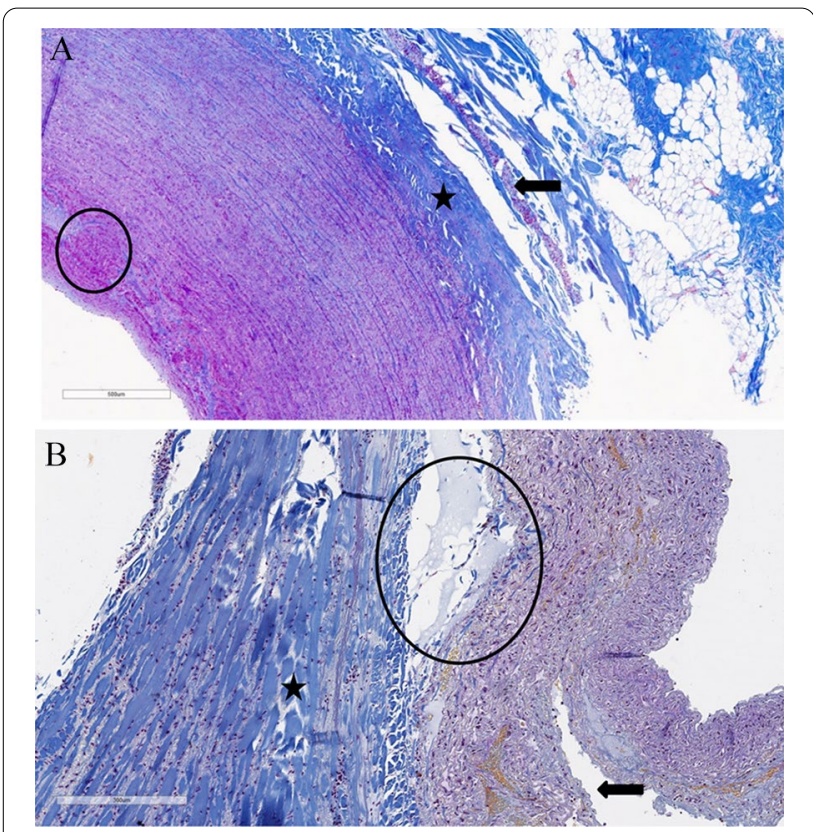

Fig. 6 Histological study of percutaneous RF-induced PA wall lesion: a Coagulation necrosis (asterisk) of adventitia with underlying unaltered nerve fiber (arrows), edema in 1/3 media (circle), $\times 50 ; \mathbf{b}$ RF-induced dissection (arrow) with transmural PA wall lesion without underlying nerve fibers (asterisk), $\times 50$

positive correlation was observed between the mean total RF lesion area per PA specimen and the animal weight $(\rho=0.65, p=0.04)$. There was a trend toward a negative correlation between SBP, DBP after PADN and the mean total RF lesion area per a PA specimen $(\rho=-0.61, p=0.059)$; and a positive correlation with the DBP difference between the baseline value and after PADN $(\rho=0.65, p=0.039)$. No significant correlation was found between type III lesion percentage and hemodynamic changes after PADN. The presence of a higher percentage of grade II and III lesions in PA was associated with HR acceleration after PADN $(\rho=0.68, p=0.03)$. A negative correlation was noted between grade I lesion percentage and diastolic BP $(\rho=-0.77, p=0.01)$ after PADN.

Groups I (PH-PADN) and II (nonPH-PADN) showed no difference in the total percentage of RF-induced lesions in the PA $(p=0.61)$ (Table 4). A negative correlation was noted between the percentage of all $\mathrm{RF}$ lesions and the DBP and $\mathrm{mBP}$ differences in PH modeling-2 $(\rho=-0.90 ; p=0.037, \rho=-0.90 ; p=0.037$, respectively). The percentage of grade III lesions in PA was not associated with hemodynamic changes after PADN, the TXA2 dose, or the time needed for $\mathrm{PH}$ modeling-2. A tendency toward a positive correlation between grade III percentage and SVR $(\rho=0.87$, $p=0.053)$ was found in $\mathrm{PH}$ modeling-2, moreover, the positive correlation with SVR during $\mathrm{PH}$ modeling-2 reached a statistically significant value when the percentage of grade II and III lesions were analyzed together $(\rho=-0.90 ; p=0.037)$.

\section{Discussion}

The results of our experimental study with reversible $\mathrm{PH}$ induction show that PADN does not lead to acute changes in mean PAP. The PADN procedure does not influence the TXA2 dosage and times to reach the target mean PAP during repeat $\mathrm{PH}$ induction. The more RF applications delivered to the PA wall, the higher number of deeper lesions with adventitial damage is found. The number of deep PA lesions is associated with HR acceleration immediately after PADN.

No substantive correlation has been observed between the number of RF applications in the PA and hemodynamic changes after PADN in the entire cohort of animals. However, the number of RF applications in group I (PH-PADN) has been associated with a significant HR, systolic PAP, RAP increase, and PVR elevation after PADN. The percentage of grade II and III lesions in the PA is associated with the degree of HR acceleration and the SVR elevation during PH modeling-2. These hemodynamic changes after PADN could be attributed to a sensitizing effect of TXA2 on the vasculature. HR elevation might be associated with the extent of perivascular nerve damage, as seen in cardiac arrhythmia ablation procedures [23]. Therefore, we suggest that HR acceleration after PADN might be a sign of extensive PA lesions and more effective denervation. In animals without $\mathrm{PH}$ modeling, PADN leads to a significant SBP drop associated with SVR decrease. A possible mechanism of systemic BP fluctuations during PADN could be attributed to the interaction between pulmonary arterial and carotid sinus baroreceptor reflexes unless general anesthesia and TXA2 could modify natural response [24, 25].

One of our key findings is that the number of RF applications positively correlates with the percentage of grade III PA lesions. This suggests that a small number of discrete PA ablations cannot be reaching the majority of perivascular neural fibers, and more excessive ablation is required for denervation. Additionally, despite the high number of severe PA wall lesions, no acute nerve fiber necrosis is observed at the sites of catheter unipolar RF ablation. We used even higher RF power ( $40 \mathrm{~W})$ than other authors $[17,18,26]$. Thus, our previous report on experimental data in swine has demonstrated that $40 \mathrm{~W}$ RF ablation induces deep lesions penetrating to PA nerve fibers [27]. The current study results show preserved nerves despite rough PA wall damage at ablation sites. Rothman et al. applied $2-8 \mathrm{RF}$ ablations $\left(>55^{\circ} \mathrm{C}\right.$; 
impedance reduction $>10 \%$; $>60$ s) to the PA trunk and its bifurcation and found a reduction in S100 expression at the sites of ablation that corresponded to the mPAP and PVR decrease in TXA2-induced acute PH in swine. We have applied a greater number of RF applications with higher energy, and no correlation of the number and lesion grade have been found associated with changes in $\mathrm{PH}$ induction. Possible causes of insufficient PADN effect and nerve damage include the absence of tight constant contact between the ablation catheter tip and the PA wall during RF application, insufficient duration of applications (30 versus 60 and $120 \mathrm{~s}$ in the other studies), and the absence of continuous circumferential damage in our experiment. However, the presence of RF-induced PA lesions suggests that catheter position and orientation are adequate in the majority of applications. The application of specially designed catheters can be more appropriated for denervation. Thus, Chen et al. established a loopshaped ablation catheter with 10 electrodes and, using $R F$ energy (temperature $50^{\circ} \mathrm{C}$, energy $\leq 10 \mathrm{~W}$, impedance $<140 \Omega$, time $20 \mathrm{~s}$.) was able to completely abolish the $\mathrm{PH}$ induced by PA balloon occlusion in dogs [28].

Although our results suggest that in the acute phase no physical destruction of perivascular fibers could be found, we speculate that in chronic experiments, delayed nerve damage might be expected. Thus, Rothman et al. demonstrated hemodynamic improvement in patients with pulmonary arterial hypertension $(\mathrm{PAH})$ at 4 months after ultrasound PADN, whereas no significant changes in hemodynamic parameters were noted immediately after the denervation procedure [8]. Zhou et al. have recorded the effect of nerve fiber degeneration 3 months after RF-PADN in dogs [26], however, Garcia Lunar has shown that transcutaneous RFA is not accompanied by a significant PA nerve destruction or transmural PA wall lesions and they observed intact PA walls near the RF application site. By contrast, surgical PADN with bipolar radiofrequency clamps (with tissue impedance monitoring for transmurality control) has led to nerve fiber damage but has not been associated with a PAP decrease in chronic pulmonary venous hypertension (PVH) either. No changes in histology or function (MRI) of the heart and pulmonary vessels are registered 3 months after surgical PADN with bipolar RF clamps in swine [17]. The reason for the absence of PAP decrease after PADN in the Lunar study could be attributed to the PVH model used. Nevertheless, the PAP decrease has been demonstrated after PADN in the majority of clinical studies which included patients with $\mathrm{PAH}$ of different origins and even in pulmonary venous hypertension patients with heart failure [5].

PA stimulation mapping of PA zones associated with sympathetic autonomic nerve response has been proposed for more targeted PA denervation [19]. However, the benefits of targeted vs non-targeted PA denervation have not been proven so far [20, 29]. In the present study, excessive PA ablation has been performed with the avoidance of sites close to the phrenic and laryngeal nerves. The number of RF ablations delivered to the PA has been significantly associated with an increase in systolic PAP immediately after PADN in swine with prior $\mathrm{PH}$ modeling-1. We suggest that TXA2 infusion and PA wall damage by RF ablation may sensitize the pulmonary vasculature to vasoconstriction, thereby leading to the systolic PAP and PVR increase directly after PADN. Duggan et al. have demonstrated that PA in swine is prone to vasoconstriction reactions and displays PA neurogenic contraction irrespective of vessel caliber on electrical stimulation [30]. Nevertheless, the trend to the diastolic PAP decrease in $\mathrm{PH}$ modeling-2 suggests the possible effect of PADN on acute PH inducibility. However, the latter assumption remains speculative.

The mechanism of the PAP decrease after PADN in patients with $\mathrm{PAH}$ is still unclear as severely remodeled PAs exhibit extremely low vasodilatation properties and nerve fibers density gradually decreases towards the periphery [31]. In this setting, acute $\mathrm{PH}$ modeling without severe histological changes in the PAs could be relevant for the evaluation of the acute PADN effect on PA vasodilatation as the probable mechanism of the mean PAP decrease. Previous reports demonstrated that PADN may potentially affect $\mathrm{PH}$ induction by $\mathrm{TxA} 2$, a potent vasoconstrictor and pro-inflammatory agent (Rothman et al. [18]). It is assumed that PADN affects the afferent neural regulation of pulmonary vasculature tonus and abolishes PA vasospasm, and, as a consequence, leads to a decrease in PA pressure in an acute period after denervation. Acute pulmonary artery pressure decrease was registered immediately after PADN in the majority of experimental and clinical studies in $\mathrm{PH}$. The lack of vasoconstriction despite repeat TXA2 infusion might be the only possible mechanism of the presumptive positive effect of PADN in this model. Another PH model that has been used in other studies is chronic hypoxic $\mathrm{PH}$, which is characterized by typical for $\mathrm{PH}$ pulmonary arteries remodeling characterized by media hypertrophy, fibrosis, and PA lumen narrowing with low vasodilative properties. Therefore, in the hypoxic $\mathrm{PH}$ model possibly weaker response to PADN had been expected. Whereas, TxA2 infusion leads to an acute and reversible mean PAP elevation without typical for chronic $\mathrm{PH}$ arterial remodeling.

Another issue is RF-induced PA wall injury with subsequent PA remodeling as well as the concomitant damage of parasympathetic nerve fibers that lie together with sympathetic ones [21,32] and mediate the PA vasodilatation effect [33]. Various types of micro-injuries including 
PA wall dissection, coagulation of media and adventitia, parietal thrombosis, and hemorrhages in different layers at the sites of RF applications and adjacent areas have been revealed on pathomorphological examination in swine [22, 27]. In chronic PVH, no significant PA wall changes have been noted 3 months after transcutaneous RF PADN [17]. Moreover, it is still unclear whether PADN influences PA remodeling on its length in swine. Unfortunately, the data on PA remodeling after PADN in rats with monocrotaline $\mathrm{PH}$ model [9] could not be transferred directly to humans or even to swine as they exhibit completely different PA innervation patterns and neurogenic responses to the adrenergic stimulation [30].

Pulmonary embolism could be another potential problem associated with PADN. Three animals from the PH-PADN group have shown acute PE with pulmonary hemodynamic deterioration. In all cases, PADN has been performed after complete normalization of hemodynamics after the termination of the first TXA2 infusion, unless platelets could remain activated. Our study implemented additional two groups: the group of PADN without TXA2 infusion and the group with double TXA2 PH induction with a sham procedure. This allows assessing the possible influence of PADN on PA thrombus generation. No PE has been revealed on the autopsy in these groups; nevertheless, we are not able to exclude a thrombogenic effect of the PADN with TXA2 infusion, which, along with vasoconstriction, activates platelets [34]. The mean number of ablation points in studies by Rothman A. et al. and Zhou et al. is less than in our study but even limited RF ablation number might lead to endothelial damage and thrombus formation predisposition. The anticoagulation protocol was not described in the study by Rothman A. et al. We used intravenous heparin with an empirical target activated clotting time $\geq 300 \mathrm{~s}$, but even this level of anticoagulation might not be enough when extensive PA endothelial damage is created. Rothman A. et al. depicted postmortem in situ thrombi at the ablation sites in PA without providing the number of animals with thrombi. Another important factor is the difference in TXA2 dosing (from 1.5 to $10.5 \mathrm{mcg} / \mathrm{kg}$ per hour in our study and from 17 to $37 \mathrm{mcg} / \mathrm{kg}$ per hour in the study by Rothman et al.); in our study, much lesser doses were used with the same target mPAP. One may note that TXA2 formulation and manufacturers were different in our study and study by Rothman A et al., suggesting different bioactivity of the agent. We suggest that the high rate of pulmonary embolism in our series might have complex reasoning, including extended PA ablation and greater TXA2 activity.

Along with previous experimental and clinical studies on PADN, the present report demonstrates the complexity of determining PADN procedure endpoints and prediction of possible subsequent effects. The establishment of the intraoperative criteria for PADN effectiveness and appropriate subject selection requires a meticulous analysis of acute and postponed hemodynamic changes. Transmurality of RF-induced PA damage is not associated with PAP changes in the acute PH modeling study or chronic pulmonary venous hypertension in swine [17]. Effective and less traumatic energy sources with accurate focusing on the targeted area may therefore be desirable for targeting PA nerves. Ultrasonic or laser energy application for PADN could potentially lead to significant nerve damage with lesser endothelial trauma and only a minimal effect on the medial layer. [35].

\section{Limitations}

The acute design of the present study does not allow assessment of the morphological and hemodynamic changes in a delayed period after PADN.

The small samples in this study only provide statistical power to detect strong correlations, and possible moderate correlations may be underestimated.

The full study protocol with hemodynamic measurements was completed in 5 out of 9 animals allocated to group I. One may expect some effect of the reduction in sample size on the reproducibility of our findings, but this reduction was expected when planning the experiment, as stated in methods, and the resulting number of animals in three groups was comparable.

We cannot fully exclude TxA2 toxic effects and delayed implication on $\mathrm{PH}$ induction during the second challenge. Although there was no statistically meaningful difference in TxA2 dose during the second challenge when compared to the first infusion, the numerical difference has a trend toward a shorter induction time. Moreover, the high rate of pulmonary embolism found in group I may be related to the combination of pro-thrombotic effects of TXA2 infusion itself and PA endothelium damage due to extensive RF ablation.

A conventional RF ablation catheter may not be fully adequate for PA denervation procedures and lead to intima damage in a high proportion of lesions; however, histologically high grades of PA damage have been found in the majority of RF applications.

Acute PH modeling with synthetic TXA2 may not be fully relevant for interventions on pulmonary arteries as the delayed vascular wall and platelet sensibilization could influence PADN effects. The TXA2 model of PH cannot reflect all forms of $\mathrm{PH}$ where PADN may still be effective in PAP reduction. 


\section{Conclusions}

In the acute experiment in swine, transcatheter PADN does not affect $\mathrm{PH}$ inducibility using TXA2. The number of RF applications delivered to the PA wall has a positive correlation with the percentage of high-grade wall lesions affecting the adventitia and perivascular adipose tissue. Significant PA adventitia damage is associated with HR acceleration after PADN. The potential effects of PADN on $\mathrm{PH}$ inducibility in a chronic experiment require further investigation.

\begin{abstract}
Abbreviations
CO: Cardiac output; DBP: Diastolic blood pressure; DPAP: Diastolic pulmonary artery pressure; HR: Heart rate; mBP: Mean blood pressure; mPAP: Mean pulmonary artery pressure; PA: Pulmonary artery; PADN: Pulmonary artery denervation; PAH: Pulmonary arterial hypertension; PAP: Pulmonary artery pressure; PCWP: Pulmonary capillary wedge pressure; PH: Pulmonary hypertension; PVR: Pulmonary vascular resistance; RAP: Right atrial pressure; RHC: Right heart catheterization; RF: Radiofrequency; SBP: Systolic blood pressure; SPAP: Systolic pulmonary artery pressure; SVR: Systemic vascular resistance; TXA2: Thromboxane A2.
\end{abstract}

\section{Supplementary Information}

The online version contains supplementary material available at https://doi. org/10.1186/s12890-021-01786-y.

Additional file 1. Supplementary materials (Table S1, Table S2, Table S3, Figure S1).

\section{Acknowledgements}

The authors thank Stepan E. Voronin, VMD, for the technical assistance and support in the organization of experiments.

\section{Authors' contributions}

NSG, OMM, DSL, and ENM contributed to the study conception and design. Material preparation, data collection, and analysis were performed by $\mathrm{HICL}$, ADV, NSG, LEK, EGK, YAS, LBM, EMA, and ENM. The first draft of the manuscript was written by NSG, HICL, EGK and ENM, and all authors commented on the manuscript. All authors read and approved the final manuscript version.

\section{Funding}

The study was supported by a grant from the Ministry of Science and Higher Education of the Russian Federation (agreement \#075-15-2020-800). The funding authority had no impact on the study design or on the interpretation of the results.

\section{Availability of data and materials}

The datasets used and/or analyses during the current study are available from the corresponding authors on reasonable request.

\section{Declarations}

\section{Ethics approval and consent to participate}

All procedures and protocols were reviewed and approved by the Institutional Animal Care and Use Committee and performed in the Preclinical and Translational Research Center of the Almazov National Medical Research Centre.

\section{Consent for publication}

Not applicable.

\section{Competing interests}

The authors declare no competing interests.
Received: 30 August 2021 Accepted: 10 December 2021

Published online: 18 December 2021

\section{References}

1. Vaillancourt M, Chia P, Sarji S, Nguyen J, Hoftman N, Ruffenach G, Eghbali M, Mahajan A, Umar S. Autonomic nervous system involvement in pulmonary arterial hypertension. Respir Res. 2017;18(1):201. https://doi.org/ 10.1186/s12931-017-0679-6.

2. Chen SL, Zhang YJ, Zhou L, Xie DJ, Zhang FF, Jia HB, Wong SS, Kwan TW. Percutaneous pulmonary artery denervation completely abolishes experimental pulmonary arterial hypertension in vivo. Eurolntervention. 2013;9(2):269-76. https://doi.org/10.4244/EIJV9|2A43.

3. Chen SL, Zhang FF, Xu J, Xie DJ, Zhou L, Nguyen T, Stone GW. Pulmonary artery denervation to treat pulmonary arterial hypertension: the singlecenter, prospective, first-in-man PADN-1 study (first-in-man pulmonary artery denervation for treatment of pulmonary artery hypertension). J Am Coll Cardiol. 2013;62(12):1092-100. https://doi.org/10.1016/j.jacc. 2013.05.075.

4. Chen SL, Zhang H, Xie DJ, Zhang J, Zhou L, Rothman AM, Stone GW. Hemodynamic, functional, and clinical responses to pulmonary artery denervation in patients with pulmonary arterial hypertension of different causes: phase II results from the Pulmonary Artery Denervation-1 study. Circ Cardiovasc Interv. 2015;8(11):e002837. https://doi.org/10.1161/CIRCI NTERVENTIONS.115.002837.

5. Zhang H, Yu W, Zhang J, Xie D, Gu Y, Ye P, Chen SL. Pulmonary artery denervation improves hemodynamics and cardiac function in pulmonary hypertension secondary to heart failure. Pulmonary Circ. 2019;9(2):2045894018816297. https://doi.org/10.1177/2045894018 816297.

6. Romanov A, Cherniavskiy A, Novikova N, Edemskiy A, Ponomarev D, Shabanov V, Losik D, Elesin D, Stenin I, Mikheenko I, Zhizhov R, Kretov E, Pokushalov E, Po SS, Martynyuk TV, Steinberg JS. Pulmonary artery denervation for patients with residual pulmonary hypertension after pulmonary endarterectomy. J Am Coll Cardiol. 2020;76(8):916-26. https:// doi.org/10.1016/j.jacc.2020.06.064

7. Rothman A, Jonas M, Castel D, Tzafriri AR, Traxler H, Shav D, Leon MB, BenYehuda O, Rubin L. Pulmonary artery denervation using catheter-based ultrasonic energy. Eurolntervention. 2019;15(8):722-30. https://doi.org/ 10.4244/EIJ-D-18-01082.

8. Rothman A, Vachiery JL, Howard LS, Mikhail GW, Lang IM, Jonas M, Kiely DG, Shav D, Shabtay O, Avriel A, Lewis GD, Rosenzweig EB, Kirtane AJ, Kim NH, Mahmud E, McLaughlain VV, Chetcuti S, Leon MB, Ben-Yehuda O, Rubin $L$. Intravascular ultrasound pulmonary artery denervation to treat pulmonary arterial hypertension (TROPHY1): multicenter early feasibility study. JACC Cardiovasc Interventions. 2020;13(8):989-99. https://doi.org/ 10.1016/j.jcin.2019.12.027

9. Huang Y, Liu YW, Pan HZ, Zhang XL, Li J, Xiang L, Meng J, Wang PH, Yang J, Jing ZC, Zhang $H$. Transthoracic pulmonary artery denervation for pulmonary arterial hypertension. Arterioscler Thromb Vasc Biol. 2019;39(4):70418. https://doi.org/10.1161/ATVBAHA.118.311992.

10. Zhang H, Chen SL. Pulmonary artery denervation: update on clinical studies. Curr Cardiol Rep. 2019;21(10):124. https://doi.org/10.1007/ s11886-019-1203-z

11. Constantine A, Dimopoulos K. Pulmonary artery denervation for pulmonary arterial hypertension. Trends Cardiovasc Med. 2021;31(4):252-60. https://doi.org/10.1016/j.tcm.2020.04.005.

12. Feshchenko DA, Rudenko BA, Shanoyan AS, Drapkina OM, Kontsevaya AV, Gavrilova NE, Shukurov FB, Vasiliev DK. Pulmonary artery denervation in patients with pulmonary hypertension: present state and clinical experience. Russ J Cardiol. 2019;(12):162-8. (in Russian) https://doi.org/10 15829/1560-4071-2019-12-162-168

13. García-Lunar I, Pereda D, Ibanez B, García-Álvarez A. Neurohormonal modulation as a therapeutic target in pulmonary hypertension. Cells. 2020;9(11):2521. https://doi.org/10.3390/cells9112521.

14. Sztuka K, Jasińska-Stroschein M. Animal models of pulmonary arterial hypertension: a systematic review and meta-analysis of data from 6126 animals. Pharmacol Res. 2017;125(Pt B):201-14. https://doi.org/10.1016/j. phrs.2017.08.003. 
15. Roehl AB, Steendijk P, Baumert JH, Schnoor J, Rossaint R, Hein M. Comparison of 3 methods to induce acute pulmonary hypertension in pigs. Comp Med. 2009;59(3):280-6.

16. Goncharova NS, Andreeva EM, Vakhrushev AD, Leandro H, Murashova LA, Voronin SE, Korobchenko LE, Mitrofanova LB, Skorik YA, Galagudza MM, Moiseeva OM, Mikhaylov EN. Modeling of acute pulmonary arterial hypertension in pigs using a stable thromboxane $\mathrm{A}_{2}$ analogue (U46619): dose adjustment and assessment of hemodynamic reactions. Bull Exp Biol Med. 2021;170(6):729-33. https://doi.org/10.1007/ s10517-021-05142-2.

17. Garcia-Lunar I, Pereda D, Santiago E, Solanes N, Nuche J, Ascaso M, Bobí J, Sierra F, Dantas AP, Galán C, San Antonio R, Sánchez-Quintana D, SánchezGonzález J, Barberá JA, Rigol M, Fuster V, Ibáñez B, Sabaté M, García-Álvarez $A$. Effect of pulmonary artery denervation in postcapillary pulmonary hypertension: results of a randomized controlled translational study. Basic Res Cardiol. 2019;114(2):5. https://doi.org/10.1007/s00395-018-0714-x.

18. Rothman AM, Arnold ND, Chang W, Watson O, Swift AJ, Condliffe R, Elliot CA, Kiely DG, Suvarna SK, Gunn J, Lawrie A. Pulmonary artery denervation reduces pulmonary artery pressure and induces histological changes in an acute porcine model of pulmonary hypertension. Circ Cardiovasc Interv. 2015;8(11):e002569. https://doi.org/10.1161/CIRCINTERVENTIONS. 115.002569 .

19. Condori Leandro HI, Vakhrushev AD, Goncharova NS, Korobchenko LE, Koshevaya EG, Mitrofanova LB, Andreeva EM, Moiseeva OM, Lebedev DS, Mikhaylov EN. Stimulation mapping of the pulmonary artery for denervation procedures: an experimental study. J Cardiovasc Transl Res. 2021;14(3):546-55. https://doi.org/10.1007/s12265-020-10079-4.

20. Goncharova NS, Moiseeva OM, Condori Leandro HI, Zlobina IS, Berezina AV, Malikov KN, Tashkhanov DM, Lebedev DS, Mikhaylov EN. Electrical stimulation-guided approach to pulmonary artery catheter ablation in patients with idiopathic pulmonary arterial hypertension: a pilot feasibility study with a 12-month follow-up. Biomed Res Int. 2020;2020:8919515. https://doi.org/10.1155/2020/8919515.

21. Koshevaya EG, Mitrofanova LB, Goncharova NS, Leandro H, Vakhrushev AD, Korobchenko LE, Murashova LA, Galagudza MM, Perminova AA, Moiseeva OM, Mikhaylov EN. Perivascular innervation of the pulmonary artery in human and swine: a comparative study for the development of an experimental model of denervation. Bull Exp Biol Med. 2020;170(2):279-82. https://doi.org/10.1007/s10517-020-05051-w.

22. Condori Leandro HI, Koshevaya EG, Mitrofanova LB, Vakhrushev AD, Goncharova NS, Korobchenko LE, Andreeva EM, Lebedev DS, Mikhaylov EN. An ovine model for percutaneous pulmonary artery laser denervation: perivascular innervation and ablation lesion characteristics. Int J Mol Sci. 2021;22(16):8788. https://doi.org/10.3390/ijms22168788.

23. Tang L, Hawkins NM, Ho K, Tam R, Deyell MW, Macle L, Verma A, Khairy P, Sheldon R, Andrade JG, CIRCA-DOSE Study Investigators. Autonomic Alterations After Pulmonary Vein Isolation in the CIRCA-DOSE (Cryoballoon vs Irrigated Radiofrequency Catheter Ablation) Study. J Am Heart Assoc; 2021 10(5), e018610. https://doi.org/10.1161/JAHA.120.018610

24. Milstein JM, Goetzman BW. Effect of pulmonary artery distention on systemic vascular resistance in newborn lambs. Am J Cardiol. 1985;56(10):681-4. https://doi.org/10.1016/0002-9149(85)91035-5.

25. Moore JP, Hainsworth R, Drinkhill MJ. Reflexes from pulmonary arterial baroreceptors in dogs: interaction with carotid sinus baroreceptors. J Physiol. 2011;589(Pt 16):4041-52. https://doi.org/10.1113/jphysiol.2011. 210732.

26. Zhou L, Zhang J, Jiang XM, Xie DJ, Wang JS, Li L, Li B, Wang ZM, Rothman A, Lawrie A, Chen SL. Pulmonary artery denervation attenuates pulmonary arterial remodeling in dogs with pulmonary arterial hypertension induced by dehydrogenized monocrotaline. JACC Cardiovasc Interv. 2015;8(15):2013-23. https://doi.org/10.1016/j.jcin.2015.09.015.

27. Koshevaya EG, Mitrofanova LB, Condori Leandro HI, Vakhrushev AD, Mikhaylov EN, Goncharova NS. Types of pulmonary artery injuries, nervous structures and environmental fat cell in the pig bifurcation area in circular radiofrequency ablation. Biomed J. 21, Art. 6; 2020 (pp. 55-74). http://www.medline.ru/public/art/tom21/art6.html.

28. Chen SL, Zhang YJ, Zhou L, Xie DJ, Zhang FF, Jia HB, et al. Percutaneous pulmonary artery denervation completely abolishes experimental pulmonary arterial hypertension in vivo. Euro Intervention. 2013; 9(2):269-76.
29. Fujisawa T, Kataoka M, Kawakami T, Isobe S, Nakajima K, Kunitomi A, Kashimura S, Katsumata Y, Nishiyama T, Kimura T, Nishiyama N, Aizawa Y, Murata M, Fukuda K, Takatsuki S. Pulmonary artery denervation by determining targeted ablation sites for treatment of pulmonary arterial hypertension. Circ Cardiovasc Interv. 2017;10(10):e005812. https://doi. org/10.1161/CIRCINTERVENTIONS.117.005812.

30. Duggan DJ, Bieger D, Tabrizchi R. Neurogenic responses in rat and porcine large pulmonary arteries. Pulmonary Circ. 2011;1(3):419-24. https:// doi.org/10.4103/2045-8932.87311.

31. Rudner XL, Berkowitz DE, Booth JV, Funk BL, Cozart KL, D'Amico EB, ElMoalem H, Page SO, Richardson CD, Winters B, Marucci L, Schwinn DA. Subtype specific regulation of human vascular alpha(1)-adrenergic receptors by vessel bed and age. Circulation. 1999;100(23):2336-43. https://doi. org/10.1161/01.cir.100.23.2336.

32. Mitrofanova LB, Perminova AA, Goncharova NS, Mikhailov EN. Histological and immunohistochemical study of nerve fibers and ganglia in the periarterial adipose tissue of the pulmonary artery bifurcation in patients with and without pulmonary hypertension. "Arterial'naya Gipertenziya" ("Arterial Hypertension"). 2019;25(5):498-509. (in Russian). https://doi.org/ 10.18705/1607-419X-2019-25-5-498-509.

33. Buels KS, Fryer AD. Muscarinic receptor antagonists: effects on pulmonary function. Handb Exp Pharmacol. 2012;208:317-41. https://doi.org/10. 1007/978-3-642-23274-9_14.

34. Li Z, Zhang G, Le Breton GC, Gao X, Malik AB, Du X. Two waves of platelet secretion induced by thromboxane $A 2$ receptor and a critical role for phosphoinositide 3-kinases. J Biol Chem. 2003;278(33):30725-31. https:// doi.org/10.1074/jbc.M301838200.

35. Alexander W, Shi Z, Iftekher F, Welsh MJ, Gurm HS, Rising G, Yanovich A, Walacavage K, Islam MN. Renal denervation using focused infrared fiber lasers: a potential treatment for hypertension. Lasers Surg Med. 2014;46(9):689-702. https://doi.org/10.1002/Ism.22290.

\section{Publisher's Note}

Springer Nature remains neutral with regard to jurisdictional claims in published maps and institutional affiliations.

\footnotetext{
Ready to submit your research? Choose BMC and benefit from:

- fast, convenient online submission

- thorough peer review by experienced researchers in your field

- rapid publication on acceptance

- support for research data, including large and complex data types

- gold Open Access which fosters wider collaboration and increased citations

- maximum visibility for your research: over $100 \mathrm{M}$ website views per year
}

At BMC, research is always in progress.

Learn more biomedcentral.com/submissions 